\title{
Energy Generation in Tyres using Piezoelectric Material
}

\author{
Aditya Pandey ${ }^{1}$, Tejas Bansal ${ }^{2}$, Amey Konde ${ }^{3}$, Rushikesh Giri ${ }^{4}$, Sarvesh Gandhi ${ }^{5}$ \\ $1,2,3,4,5$ UG. Student, School of Mechanical Engineering \\ Dr. Vishwanath Karad's MIT World Peace University \\ Pune, India.
}

\begin{abstract}
In the project, Energy is being harnessed from the tyres with the help of Piezoelectric material. The energy dissipated by the wheels to the surrounding can be captured and transformed into electrical energy. Tyres are a good source of pulsating/alternating force which can be converted into alternating current. The tyres experience undulations and vibrations while braking as well as accelerating, vertical reaction forces while riding over bumps and potholes, hence justifying the need of a mechanism. This mechanism has vast applications and can open the door to endless innovative ideas for energy harvesting in Automobile sector and subsequent fields.
\end{abstract}

Keywords- Energy Harvesting, Piezoelectric effect, Piezoelectric material, Ceramics, Tyres, Power generation.

\section{INTRODUCTION}

With the everyday developing and growing world, there is also a growing demand for energy supplies. With the increase in demand there is an increase in concern in the depletion of resources used to generate energy the traditional way. Society is developing new alternative non-conventional methods which are gaining much popularity in today's world. Many popular and successful methods are the Solar cells, Wind energy, hydroelectric energy, geothermal, biogas plants. With the evergrowing Automotive industry and introduction of HEV's and EV's, a lot of energy is required to mobilize them. There is a need to cater this energy. Piezoelectric material and effect play a major role in solving this problem. The vibrations and undulations from the vehicular motion can be converted into electrical energy using piezoelectric effect. Tyres of the vehicle are subjected to normal and shear loads, this load can be used as the source of mechanical stress for the piezoelectric material. This project is based on a case study on a tyre of Tata Nexon EV currently running on road.

\section{THEORY}

A. Piezoelectric effect

Piezoelectricity is the property of dielectric materials to physically deform when an electric field is present, or conversely, to produce an electrical charge when they are mechanically deformed, this property is also known as Piezoelectric effect. There are a variety of materials which show this phenomenon such as natural quartz crystals, semicrystalline polyvinylidene polymer, polycrystalline piezoceramic, bone and even wood.
When piezoelectric material is placed under mechanical stress the spontaneous separation of charge with certain crystal structures under the right conditions, which results in an external electrical field. This phenomenon, referred to as spontaneous polarization, is caused by a displacement of the electron clouds relative to their individual atomic centers, i.e., a displacement of the positive ions relative to the negative ions within their crystal cells. Such a situation produces an electric dipole.

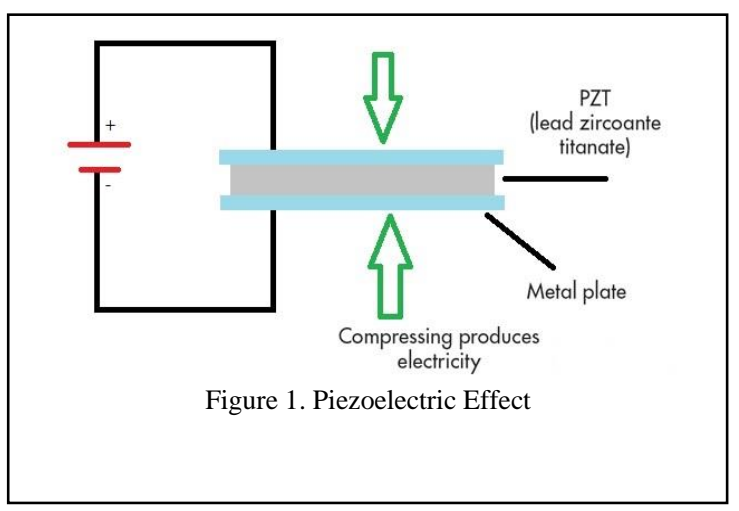

\section{B. Piezoelectric material and material selection}

There are many natural and man-made piezoelectric materials currently in use. Some of the naturally occurring materials are Sucrose (table sugar), Rochelle salt (Produces a large voltage with compression; used in early crystal microphones), Topaz, Tourmaline, Berlinite $\left(\mathrm{AlPO}_{4}\right.$; a rare phosphate mineral structurally identical to quartz). Some of the piezoelectric ceramics are Barium titanate $\left(\mathrm{BaTiO}_{3}\right)$. Potassium niobate $\left(\mathrm{KNbO}_{3}\right)$, Lithium niobate $\left(\mathrm{LiNbO}_{3}\right)$, Lithium tantalate $(\mathrm{LiTaO})$, Sodium tungstate $\left(\mathrm{Na}_{2} \mathrm{WO}_{4}\right)$, Lead titanate $\left(\mathrm{PbTiO}_{3}\right)$. Lead zirconate titanate or PZT is currently the most used piezoelectric ceramics and used in many applications. 
Piezoelectric material properties:

$\mathrm{d}_{\mathrm{ij}}$ - This piezoelectric constant is the ratio of mechanical strain to applied electric field at constant stress $(\mathrm{m} / \mathrm{V})$. Conversely, it is the ratio of electric displacement to mechanical stress at constant electric field $(\mathrm{C} / \mathrm{N})$, ' $\mathrm{i}$ ' indicates that the electrodes are perpendicular to ' $i$ ' no. of axes and ' $j$ ' indicates that the piezoelectricity induced strain, or the applied stress, is in direction ' $\mathrm{j}$ ' [1].

$\mathrm{g}_{\mathrm{ij}}$ - This piezoelectric constant is the ratio of electric field to applied mechanical stress at constant electric displacement $(\mathrm{Vm} / \mathrm{N})$. Conversely, it is the ratio of mechanical strain to electric displacement at constant stress $\left(\mathrm{m}^{2} / \mathrm{C}\right)$.

Curie temperature - This is the temperature above which the crystal structure changes to a symmetrical, non-piezoelectric form. The dielectric constant peaks and the net polarization completely disappears at the Curie temperature.

\section{Properties of PZT}

- Dielectric constant $(@ 1 \mathrm{KHz})=1800$

- Piezoelectric strain coefficient, $\mathrm{d}_{33}=390 \times 10^{-12} \mathrm{~m} / \mathrm{V}$

- Piezoelectric Voltage coefficient, $\mathrm{g}_{33}=24 \times 10^{-3} \mathrm{Vm} / \mathrm{N}$

- Elastic Modulus = $4.9 \times 1010 \mathrm{~N} / \mathrm{m} 2$

- Compressive strength $=5.2 \times 10^{8} \mathrm{~N} / \mathrm{mm}^{2}$

- Tensile Strength: (Static) $=7.5 \times 10^{7} \mathrm{~N} / \mathrm{mm}^{2}$

$$
(\text { Dynamic })=2 \times 10^{7} \mathrm{~N} / \mathrm{mm}^{2}
$$

- Curie Temperature $=350^{\circ} \mathrm{C}$ [2]

Due to its desired properties such as high compressive and tensile stress, and a high Curie temperature to withstand the heat during the vulcanization process, PZT-5A have been selected as the piezoelectric material in this project.

\section{Packaging of PZT}

PZT-5A - is best for applications that have extreme temperatures and/or a widely varying temperature but the performance is desired to remain constant.

Tyre faces continuous forces acting on it, PZT being brittle may not withstand these continuous loads. To make the PZT modules robust packaging is a must. While packaging the piezo wafers are sandwiched between thin, flexible circuits. Typically, either FR4 is used (like those in a standard printed circuit board) or Polyimide for the flex circuits, but any circuit material can theoretically be used.

A layer of high-temperature polysulfone plastic is used to align all the layers to the copper connections in the flex circuits. Finally, a high-temperature epoxy is used to adhere all the layers together in the packaging process. This creates a robust, hermetically sealed, electrically insulated transducer with easy connection. Packaging also reduces the risk of lead exposure [3].

\section{ORIENTATION OF PZT MODULES}

\section{A. Tyre composition}

Selected tyre for the project: - Tata Nexon has a tyre size of 215/60 R16 [4].

Where 215 - is the width of the tyre

60 - is the aspect ratio

$\mathrm{R}$ - signifies it is Radial

16 - is the rim diameter

The height of the tyre will be $(60 \times 215) / 100=129 \mathrm{~mm}$.

\begin{tabular}{|c|c|c|c|c|c|c|c|c|}
\hline Properties & Units & FR4 & Copper & Polyimide & $\begin{array}{l}304 \\
\text { Steel }\end{array}$ & Polysulfone & Polyester & Brass \\
\hline $\begin{array}{l}\text { Youn's } \\
\text { Modulus }\end{array}$ & $\mathrm{GPa}_{3}$ & 26 & 110 & 4.1 & 193 & 5.72 & 3.65 & 100 \\
\hline 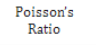 & & 0.17 & 0.34 & 0.34 & 0.29 & 0.4 & 0.48 & 0.32 \\
\hline Density & $\mathrm{g} / \mathrm{cc}$ & 1.9 & 8.93 & 1.81 & 8.00 & 1.37 & 1.38 & 8.30 \\
\hline $\begin{array}{l}\text { Ultimate } \\
\text { Tensile Stress }\end{array}$ & $\mathrm{MPa}$ & 368 & 210 & 231 & 505 & 81 & 177 & 800 \\
\hline $\begin{array}{c}\text { Tensile Yield } \\
\text { Strength }\end{array}$ & $\mathrm{MPa}$ & 340 & 33.3 & 90 & 215 & 87.9 & 92.8 & 500 \\
\hline $\begin{array}{l}\text { Thermal } \\
\text { Expansion } \\
\text { Coefficient }\end{array}$ & $\underset{c}{\mu m / m-}$ & 15 & 16.4 & 34.3 & 17.3 & 31 & 17 & 22.0 \\
\hline $\begin{array}{c}\text { Thermal } \\
\text { Conductivity }\end{array}$ & $\mathrm{W} / \mathrm{m}-\mathrm{K}$ & 0.4 & 398 & 0.26 & 16.2 & 0.26 & 0.15 & 200 \\
\hline Specific Heat & $J / g-C$ & 0.6 & 0.39 & 1.09 & 0.5 & 910 & 1.17 & 0.38 \\
\hline $\begin{array}{c}\text { Max. } \\
\text { Operating } \\
\text { Temperature }\end{array}$ & c & 130 & 1083 & 275 & 1400 & 160 & 220 & 750 \\
\hline
\end{tabular}

Figure 2. Properties of packaging materials

There is a wide range of material used for making a tyre. The basic materials are: carbon black for wear resistance, silica as a high-grade material that ensure short stopping distance on wet road it is one of the important materials in tread and other additives such as antioxidants which protect the tire against premature aging, natural rubber and synthetic rubber. The secondary material which is used to vary the property of the basic compound for the respective application are: chalk, oils, resin, accelerating agent, retardants, compounding promoters, activators and Sulphur.

There are different layers in tyres and the function of each layer is different:

1. Inner liner: It is the innermost layer of the tyre. It is a thin airtight layer made up from a composition of rubbers. It replaces the tubes present the previous generation tyres.

2. Ply (above the inner liner): It consists of thin textile cords covered with rubber compound in radial direction. It acts as a reinforcement material. It also determines the load rate of tyre and the cushioning factor.

3. Bead and Apex: Bead is a combination of steel wires covered with rubber compounds. It keeps the tyre seated on the rim. Apex is a series of steel cord along the height of the tyre or side wall. Apex provides driving stability and improves steering performance.

4. Breaker: Breaker is a layer of rubber coated steel cord placed at an acute angle to the axis of tyre. It maintains rigidity of tread in longitudinal and lateral direction. It ensures power transmission during driving and ensures stable cornering. It also increases the resistance to wear. There are two layers of breaker in tyre present at the opposite direction to each other.

5. After the breaker there is a layer of nylon in the form of a net. It helps to maintain the shape of the tyre when it is at high speed and temperature.

6. Tread: It is the layer which comes in contact with the road. It improves grip and durability of tyre and reduces rolling resistance.

7. Before the vulcanization process; the tread, cap ply, and breaker are considered as one unit and the bead, apex, inner linear and ply as another. During assemblage these are brought together.

\section{B. Orientation of Piezo-electric}


- Unit 1: During the manufacturing process the first layer will be an inner liner followed by a layer of ply with the bead and the apex on the sides. After these layers are placed on the machine, the layer of piezoelectric sensor would be placed on top of the ply. Before applying the side wall to the unit, the piezoelectric wiring is taken out for later connection. The side wall's layer is placed above the wiring. Using these arrangements, the wire connection is concealed within the tyre. - Unit 2: the bottom layer comprises of two layers of breaker, followed by cap ply and the layer of tread.

\section{Assemblage}

Unit 2 is placed over unit 1 which are glued together by applying air pressure. Then the assembly is sent for vulcanization.

Vulcanization is a process in which the hot steam is passed through the membrane which is in contact with the inner side of the tyre. The outer side of the tyre is in contact with the mold which is also known as curing mold. In this process the tire gets its marking and tread pattern. Because of the temperature, all layers inside of the tire become one. The temperature range is between $170-200$ degree $\mathrm{C}$ and at pressure of 22 bar for around $10 \mathrm{~min}$. The values depend on the size of the tyre.
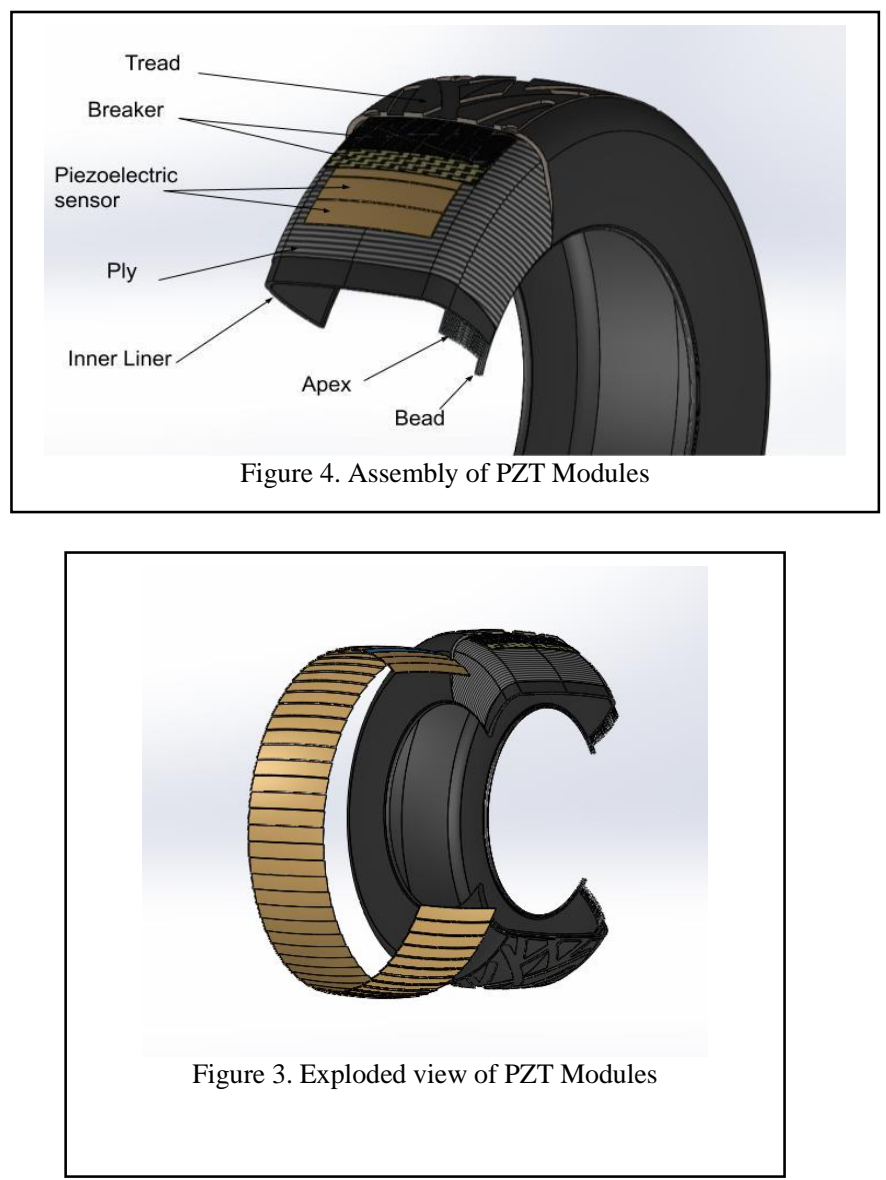

\section{DIMENSIONS OF PZT MODULES}

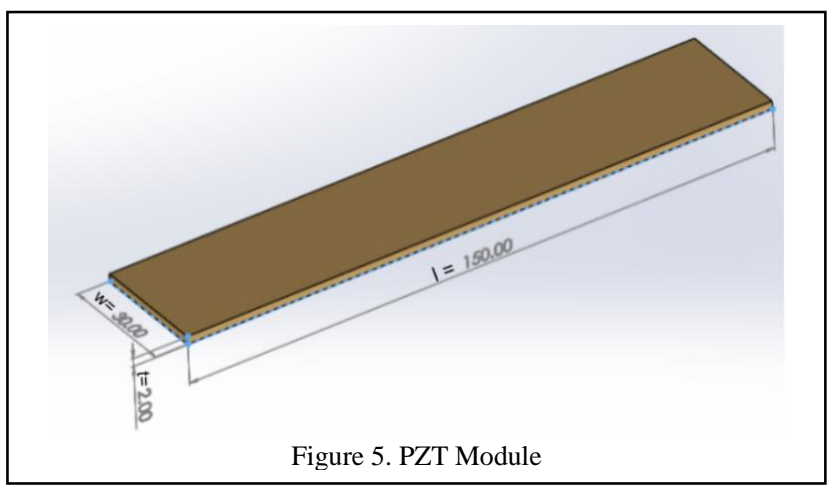

A. Length (l)

The specifications of the Tata Nexon EV tyre are 215/60 R16, therefore the width of the tyre is $215 \mathrm{~mm}$. Assuming the thickness of the sidewall as $20 \mathrm{~mm}$, and by providing some clearance space for the wiring and mountings $(10 \mathrm{~mm}$ on each side), $150 \mathrm{~mm}$ of total free space was available and hence customized the piezoelectric sensors to the desired length of $150 \mathrm{~mm}$.

\section{B. Width $(w)$}

The width of the plates is dependent on the contact patch area of the tyre; therefore, the contact patch area is:

For Tata Nexon EV the Tire Pressure is 35 psi, which is 0.2413 $\mathrm{N} / \mathrm{mm}^{2}$

Area $=($ Force on the wheel $) /($ Tire Pressure $)$

Area $=456.25 \times 9.18 / 0.2413=18548.746 \mathrm{~mm}^{2}$

Therefore, $18548.746 \mathrm{~mm}^{2} / 150 \mathrm{~mm}=123.66 \mathrm{~mm}$

Therefore, a single plate of $120 \mathrm{~mm}$ can be used or multiple plates of lower dimension (greater the number of plates, greater is the uniform weight distribution over the plate). Therefore, 4 plates of width $30 \mathrm{~mm}$ were finalized with a spacing of $1 \mathrm{~mm}$ in between them.

\section{Number of plates}

The location of the piezoelectric sensors is assumed to be 20 $\mathrm{mm}$ below the outer surface (tread) of the wheel. Therefore, the diameter of the location is $624.4 \mathrm{~mm}$. Since, the width of the plate is $30 \mathrm{~mm}$ and the clearance in between them is $1 \mathrm{~mm}$, the total number of plates is:

$=(624.4 \times \pi) /(30+1)$

$=63.277 \approx 63$ plates

\section{Thickness $(t)$}

The thickness of the piezoelectric plate is directly proportional to the energy generated by it, but with increase in the thickness, the physical properties of the material is emphasized resulting in higher brittleness. Also, a thicker plate would hamper the properties of the tyre which is not preferred.

Therefore, an optimum thickness has to be selected for the most efficient and physically viable power generation. Since the thickness of plies is greater than 3mm [5], piezoelectric plates of $2 \mathrm{~mm}$ thickness have been finalized. 


\section{Detailed Mathematical CAlCUlations}

\section{A. Division of Vehicle load}

Kerb Weight of the vehicle $=1400 \mathrm{~kg}$

Weight of passengers $=(5 \times 85)=425 \mathrm{~kg}$.

Since the vehicle is a TATA Nexon EV which is a 5-seater and assuming that the weight of each passenger is $85 \mathrm{~kg}$.

Gross weight $=$ Kerb weight + Weight of passenger

$=(1400+425) \mathrm{kg}=1825 \mathrm{~kg}$

Taking the weight distribution of the vehicle as (50-50), the load on the front and rear wheels are:

Front wheels $=50 \%$ of $1825 \mathrm{~kg}=912.5 \mathrm{~kg}$

Rear wheels $=50 \%$ of $1825 \mathrm{~kg}=912.5 \mathrm{~kg}$

Since the load on the front and rear wheels is same, load on each wheel $=912.5 / 2=456.25 \mathrm{~kg}$.

\section{B. Contact Patch Area}

It is the area which will be in contact with the surface when the vehicle is at rest or in motion.

To calculate Contact Patch Area, the pressure of the tyre is needed.

For Tata Nexon EV, the Tire Pressure is $35 \mathrm{psi}\left(0.2413 \mathrm{~N} / \mathrm{mm}^{2}\right)$ Contact Patch Area $=($ Force on the wheel $) /($ Tire Pressure $)$

Contact Patch Area $=456.25 \times 9.18 / 0.2413$

$=18548.746 \mathrm{~mm}^{2}$.

C. Voltage

The voltage generated is directly proportional to the induced mechanical stress $(\sigma)$. Therefore, Open Circuit Voltage (OCV) of the ceramic plates is calculated.

Induced mechanical stress $(\sigma)$ is:

$\sigma=$ Force on each ceramic plate/Area of the ceramic plate

$\sigma=456.25 \times 9.81 / 3 \times(0.015 \times 0.03)$

$\sigma=331540.7407 \mathrm{~N} / \mathrm{m}^{2}$

Therefore, the generated open circuit voltage is:

O.C. $\mathrm{V}=\mathrm{g}_{33} \times \sigma \times \mathrm{t}$

O.C.V $=24 \times 10^{-3} \times 331540.7407 \times 0.002$

O.C.V $=15.914 \mathrm{~V}$

\section{Charge density}

Charge Density is defined as the amount of electric charge per unit length.

Charge Density $=\mathrm{d}_{33} \times \sigma$

Charge Density $=390 \times 10^{-12} \times 331540.740$

Charge Density $=1.3 \times 10^{-4} \mathrm{~N} / \mathrm{Vm}$

\section{E. Charge on Each Plate}

Since the voltage generated and the charge density of the plate is known, the charge on each plate is:

Charge on each plate $=$ Charge Density $\times$ Area of a single plate Charge on each plate $=1.3 \times 10^{-4} \times(0.15 \times 0.03)$

Charge on each plate $=5.85 \times 10^{-7} \mathrm{Nm} / \mathrm{V}=5.85 \times 10^{-7} \mu \mathrm{W}$

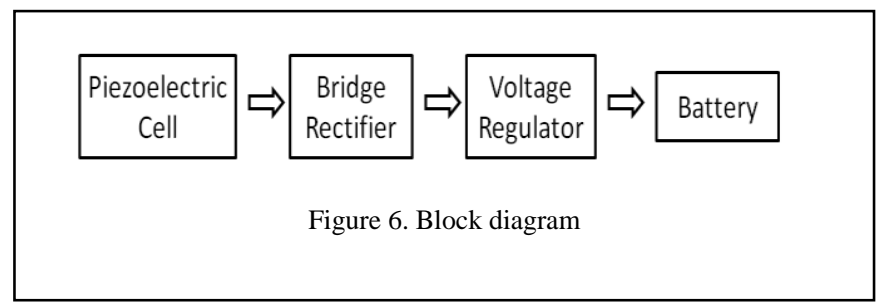

\section{F. Power}

To calculate the Power generated by a single plate:

Power $=$ Voltage $\times$ Charge

Power $=15.914 \times 0.585$

Power $=9.30969 \mu \mathrm{W}$

$G$. There are a total 63 piezoelectric plates in a single tire. Therefore, the power generated by a single rotation of a tire is: Total Power for 63 plates $=63 \times 9.30969=586.51 \mu \mathrm{W}$ per rotation.

$H$. Assuming that the vehicle is being driven at a velocity of $80 \mathrm{~km} / \mathrm{hr}$ i.e. $22.22 \mathrm{~m} / \mathrm{sec}$.

For $22.22 \mathrm{~m} / \mathrm{sec}$

$\mathrm{RPM}=$ velocity/circumference of the tire

$\mathrm{RPM}=22.22 / \pi \times 0.6644=10.64$ rotation $/ \mathrm{sec}$

I. Power output on wheel:

Power output per second per wheel $=10.64 \times 589.51$

Power output per second per wheel $=6240.4664 \mu \mathrm{W}$

$J$. The Power output from 4 wheels in 1 second.

$=6240.4664 \times 4$

$=24961.8656 \mu \mathrm{W}$

$K$. Power output in 1 hour

$=24961.8656 \times 3600$

$=89862716.16 \mu \mathrm{W}$

\section{Power output from the vehicle is $89.86 \mathrm{Wh}$}

\section{ELECTRICAL}

The PZT units are connected in parallel as current obtained is more than that of series connection. The output from the PZT unit is AC, which cannot be used to charge the battery. Therefore, a Full Wave Rectifier is used to convert AC to DC. The Rectifier consists of 4 or more diodes arranged in the bridge circuit configuration. The bridge rectifier consists of 4 diodes D1, D2, D3, and D4 in which the AC input of PZT is supplied across two terminals while the DC output is stored in the battery through the remaining two terminals. The AC consists of two cycles:

1. Positive half cycle: During this cycle diodes D1 and D2 are in forward bias while D3 and D4 are in reverse bias. The current flows through diode D1, then through the load, and finally completing the circuit by passing through D2.

2. Negative half cycle: During this cycle diodes D3and D4 are in forward bias while D1 and D2 are in reverse bias. The current flows through diode D3, then through the load, and finally completing the circuit by passing through D4.

During both cycles, the current passes through the load. Hence converting both half cycles of input AC to pulsating DC.

The DC output which we get consists of some ripples. To reduce these ripples, a filter is used. A capacitor is used as a filter which is connected across the battery. For getting constant 
voltage, a voltage regulator is used, which is connected across the output of the bridge rectifier and load as shown in the figure.

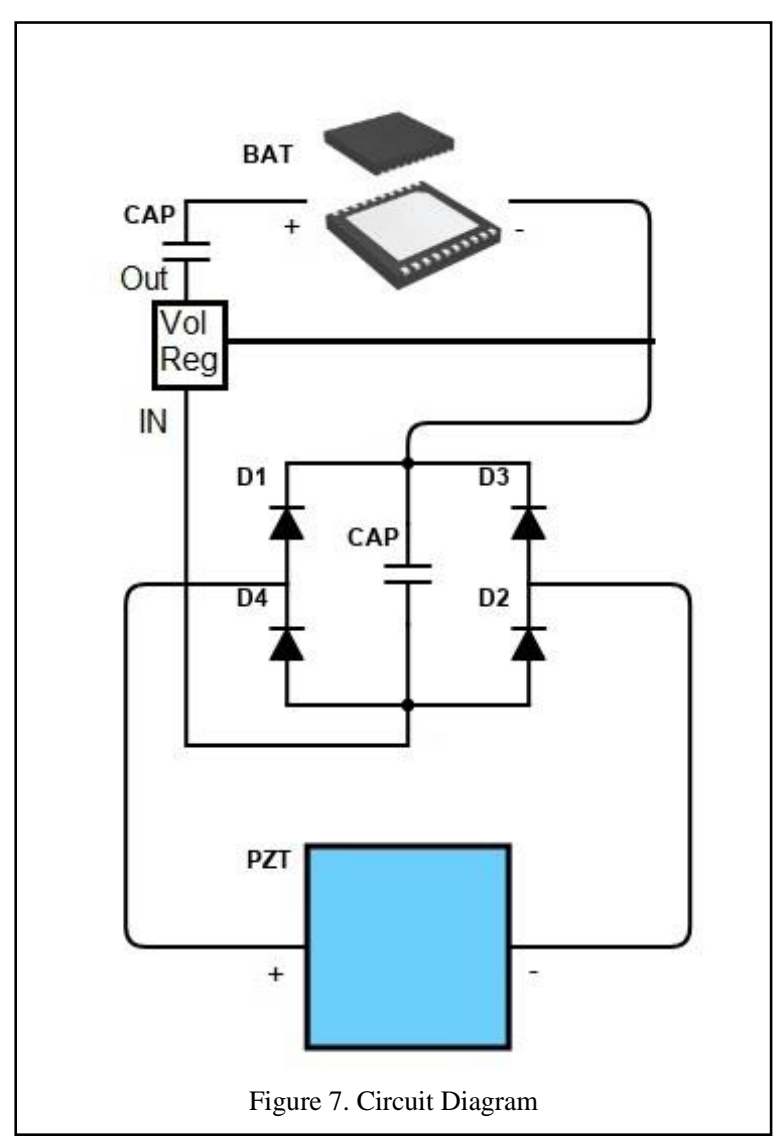

B. Selection of diode

For the selection of diode, we considered the following terms: 1. PIV (Peak Inverse Voltage): It is the maximum voltage that the diode can block when it is in reverse bias, if it exceeds that value it gets damaged. The value of PIV must be higher than the input voltage needed for the filter.

The maximum value of Voltage for a single tyre is $15.914 \mathrm{~V} \approx$ $16 \mathrm{~V}$. Therefore, we need a diode having PIV greater than $16 \mathrm{~V}$. 2. If (Average Forward Current): It is current flowing through the diode when it is forward bias.

3. Ifm (Repetitive Surge Current): It is the maximum current which the diode can carry.

Ifm for a single tyre is $0.585 \mu \mathrm{A} \times 63=36.855 \mu \mathrm{A}$.

4. Vf (Forward Voltage Drop): It is the voltage across the diode when it is in forward bias. It should be as low as possible.

5. Operating Temperature: It is the temperature range in which a diode can work without getting damaged.

\section{RESULT}

The power output in 1 hour when the vehicle is driven at 80 $\mathrm{kmph}$ is $89.8627 \mathrm{Wh}$. The mechanism is capable of generating
89.86Wh which can provide an extension of $1 \mathrm{~km}$ in Tata Nexon EV for every $80 \mathrm{kms}$ driven per hour.

\section{CONCLUSION}

The study proves that the mechanism is not efficient enough to generate energy required to fully energize any vehicle, but it can be used to increase the range of the same. This mechanism has vast applications which can revolutionize the future of electric vehicles. The study also justifies the need of advancements in the material selection for the piezoelectric sensors.

\section{APPLICATIONS}

Piezoelectric sensors have a wide range of applications out of which, harvesting of energy is the most important one. The energy harnessed from the alternating/pulsating force exerted on the wheels can be used to energize various objects like:

1. A $48 \mathrm{~V}$ Lithium ion battery which can act as a power source for electric two-wheelers

2. This mechanism can be installed in transportation vehicles to harness energy which can be further sold to the electric vehicle power stations.

\section{FUTURE SCOPE}

1. The mechanism can be installed and various other components of an automobile, for ex: suspension system and harness energy. Piezoelectric plate can be fitted in between the leaves of a leaf suspension and also in between the gaps of a damper spring to generate electricity.

2. Advanced substitutes for the conventional piezoelectric material have to be invented which are more flexible, cheaper and highly efficient.

\section{References}

[1] Electro-ceramics products and material specification Harris Technology to connect, inform and protect www.Harris.com

[2] https://piezo.com/pages/piezo-material

[3] https://support.piezo.com/article/62-material-properties

[4] https://cars.tatamotors.com/suv/nexon/specifications

[5] https://www.olympus-ims.com/en/applications/measuring- thicknessrubber-

tires/\#: :text=These $\% 20$ gages $\% 20$ are $\% 20$ used $\% 20$ mostly, $0.010 \% 20 \mathrm{i}$ n.) $\% 20$ or\%20better.

[6] Ayan Bhattacharya, "Piezoelectric Energy Harvesting in Automobile Wheel”, IJTRE, Vol.5, Issue 11, July 2018.

[7] Muhammad Kamran, Dr. Raziq Yaqub, Dr. Azam ul Asar, "Autonomously Battery Charging Tyre for EVs using Piezoelectric phenomenon", Int'l Conf., Modeling, Sim. and Vis. Method, MSV'17. 